\title{
A randomized controlled trial of stapled versus ultrasonic transection in distal pancreatectomy
}

\author{
Luca Landoni ${ }^{1}$ - Matteo De Pastena ${ }^{1}$. Martina Fontana ${ }^{1}$. Giuseppe Malleo ${ }^{1}$ Alessandro Esposito ${ }^{1}$ Luca Casetti $^{1}$. \\ Giovanni Marchegiani ${ }^{1}$ - Massimiliano Tuveri ${ }^{1}$ - Salvatore Paiella ${ }^{1}$. Antonio Pea ${ }^{1}$. Marco Ramera ${ }^{1}$. Alex Borin ${ }^{1}$. \\ Alessandro Giardino ${ }^{2}$ - Isabella Frigerio ${ }^{2}$. Roberto Girelli ${ }^{2}$. Claudio Bassi ${ }^{1}$ - Giovanni Butturini ${ }^{2} \cdot$ Roberto Salvia $^{1,3}$
}

Received: 29 March 2021 / Accepted: 30 August 2021 / Published online: 13 September 2021

(c) The Author(s) 2021

\begin{abstract}
Background The pancreatic transection method during distal pancreatectomy is thought to influence postoperative fistula rates. Yet, the optimal technique for minimizing fistula occurrence is still unclear. The present randomized controlled trial compared stapled versus ultrasonic transection in elective distal pancreatectomy.

Methods Patients undergoing distal pancreatectomy from July 2018 to July 2020 at two high-volume institutions were considered for inclusion. Exclusion criteria were contiguous organ resection and a parenchymal thickness $>17 \mathrm{~mm}$ on intraoperative ultrasound. Eligible patients were randomized in a 1:1 ratio to stapled transection (Endo GIA Reinforced Reload with Tri-Staple Technology ${ }^{\circledR}$ ) or ultrasonic transection (Harmonic Focus ${ }^{\circledR}+$ or Harmonic Ace ${ }^{\circledR}+$ shears). The primary endpoint was postoperative pancreatic fistula. Secondary endpoints included overall complications, abdominal collections, and length of hospital stay.

Results Overall, 72 patients were randomized in the stapled transection arm and 73 patients in the ultrasonic transection arm. Postoperative pancreatic fistula occurred in 23 patients (16\%), with a comparable incidence between groups (12\% in stapled transection versus $19 \%$ in ultrasonic dissection arm, $p=0.191)$. Overall complications did not differ substantially ( $35 \%$ in stapled transection versus $44 \%$ in ultrasonic transection arm, $p=0.170$ ). There was an increased incidence of abdominal collections in the ultrasonic dissection group (32\% versus $14 \%, p=0.009$ ), yet the need for percutaneous drain did not differ between randomization arms $(p=0.169)$. The median length of stay was 8 days in both groups $(p=0.880)$. Intraoperative blood transfusion was the only factor independently associated with postoperative pancreatic fistula on logistic regression analysis (OR 4.8, 95\% CI 1.2-20.0, $p=0.032$ ).

Conclusion The present randomized controlled trial of stapled versus ultrasonic transection in elective distal pancreatectomy demonstrated no significant difference in postoperative pancreatic fistula rates and no substantial clinical impact on other secondary endpoints.
\end{abstract}

Keywords Distal pancreatectomy $\cdot$ Pancreatic fistula $\cdot$ Stapler $\cdot$ Ultrasonic dissection

Luca Landoni and Matteo De Pastena shared first authorship.

Giovanni Butturini and Roberto Salvia shared senior authorship.

Roberto Salvia

roberto.salvia@univr.it

1 Unit of General and Pancreatic Surgery, University of Verona Hospital Trust, Verona, Italy

2 Unit of HPB Surgery, Pederzoli Hospital, Peschiera del Garda, Italy

3 Unit of General and Pancreatic Surgery, G.B. Rossi Hospital, University of Verona - DSCOMI, P.Le Scuro 10, 37134 Verona, Italy

\section{Introduction}

Most of the research endeavors targeting risk factors for postoperative fistula (POPF) after distal pancreatectomy (DP) focused on the pancreatic transection method, a modifiable variable with the potential for improving fistula rates $[1,2]$. The proposed technical variants included sharp transection with handsewn closure (using mattress or fish-mouth sutures), stapled transection, transection with energy-based devices (diathermy, ultrasonic devices, with or without ligation of the main pancreatic duct), or even anastomosis of the pancreatic stump to a Roux-en-Y jejunal limb or as 
a pancreaticogastrostomy [3-7]. Furthermore, the use of additional biologic sealants or stump reinforcement with an omental or falciform ligament patch have been investigated with mixed results $[8,9]$. Remarkably, none of these techniques have demonstrated a clear superiority over the others in randomized controlled trials $[10,11]$. Staplers and energy-based devices have been increasingly adopted in the last decade because of the more frequent use of minimally invasive approaches and the easy, fast, and reproducible mechanism of action. Recently a new type of triple-row stapler reinforced with a preloaded bioabsorbable polyglycolic acid (PGA) felt has been marketed, with preliminary data showing a decrease in the incidence and severity of POPF compared with the standard stapler and with ultrasonic devices, provided a pancreatic thickness $<17 \mathrm{~mm}$ [12-14]. In a recent retrospective, propensity-score matched analysis of 184 patients we suggested that the use of the triple-row reinforced stapler was associated with a sharp reduction of POPF rates relative to the ultrasonic dissector group (12\% versus $40 \%$ ) [15]. Under these premises, we sought to evaluate in a randomized trial whether parenchymal transection using the triple-row reinforced stapler decreases the incidence of POPF following DP compared with ultrasonic transection.

\section{Methods}

\section{Study design and participants}

This study is a bicentric, patient-blinded, randomized clinical trial conducted from July 2018 to July 2020 at the Unit of General and Pancreatic Surgery, University of Verona Hospital Trust, Verona, Italy; and the Unit of HPB Surgery, Ospedale Pederzoli, Peschiera del Garda, Italy. The study protocol was approved by the Ethics Committee of the Provinces of Verona and Rovigo (\#1664CESC) and registered at ClinicalTrial.gov (NCT03880773). The trial was performed in accordance with the good clinical practice guidelines, the principles of the Declaration of Helsinki, and the Consolidated Standards of Reporting Trials (CONSORT) Guidelines [16]. Patients between the ages of 18 and 80 with any indication for elective DP were eligible for inclusion. All eligible patients provided written informed consent at the time of hospital admission. The CONSORT flowchart is reported in Fig. 1.

\section{Randomization and masking}

The randomization process was as follows: on intraoperative exploration, patients were excluded if an extended DP was needed. This involved a posterior Radical antegrade modular pancreatosplenectomy (RAMPS) for left adrenal/kidney infiltration or a synchronous arterial resection (celiac trunk or hepatic artery) or an associated bowel resection. Synchronous venous resection was not an exclusion criterion. In eligible patients, pancreatic thickness was measured at the point of parenchymal transection via intraoperative ultrasound. Only patients with a parenchymal thickness $<17 \mathrm{~mm}$ were enrolled in the trial and randomized by telephone in a 1:1 ratio using a computer-generated randomization list kept by independent data managers at the coordinating center (Unit of General and Pancreatic Surgery, University of Verona Hospital Trust) and concealed to the investigators. Patients were blinded to the arm allocation during the postoperative course. The 17-mm cutoff was used to avoid staple closure failure or parenchymal crushing, according to previous evidence $[12,17]$. Post-randomization drop-out occurred in the instance of positive transection margin on frozen section analysis, requiring further resection up to total pancreatectomy.

\section{Procedures}

DP were performed by specialized pancreatic surgeons who completed the learning curve and had a personal annual caseload exceeding 50 major pancreatic resections and had completed the learning curve for both open and minimally invasive DP. All surgeons were familiar with both stump management techniques used in this trial. DP was performed either via laparotomy or minimally invasive approaches (laparoscopic or robot-assisted), with or without spleen preservation [18-20]. The level of pancreatic transection at the neck, body, or tail, depended on the nature and the location of the lesion. Stapled transection was performed using an Endo GIA Reinforced Reload with Tri-Staple Technology ${ }^{\circledR}$ (COVIDIEN, North Haven, CT, USA). Either a purple $(3 \mathrm{~mm})$ or black $(4 \mathrm{~mm})$ cartridge was employed according to the single surgeon's preference. A gradual compression was applied for 2-3 min, the stapler was then fired and slowly released after transection. Ultrasonic transection was performed using the Harmonic Focus ${ }^{\circledR}+$ Shears (open surgery) or the Harmonic Ace ${ }^{\circledR}+$ Shears (minimally invasive surgery), HARMONIC, Johnson \& Johnson Medical, Ethicon, Tokyo, Japan. Ultrasonic technology uses high-frequency mechanical energy that cuts by cavitational fragmentation and simultaneously seals tissues by coaptive coagulation [21]. The pancreas was transected at the lowest vibration level, no additional sutures were placed in the pancreatic stump or the main pancreatic duct. The Institutional policy regarding the intraoperative blood transfusion is very strict, with transfusions being indicated for $\mathrm{Hb}$ levels $<8 \mathrm{mg} /$ $\mathrm{dL}$ or for hemodynamic instability. In both arms an easyflow drain was placed in the proximity of pancreatic stump. Postoperative drain management was described elsewhere 
Fig. 1 The CONSORT flowchart

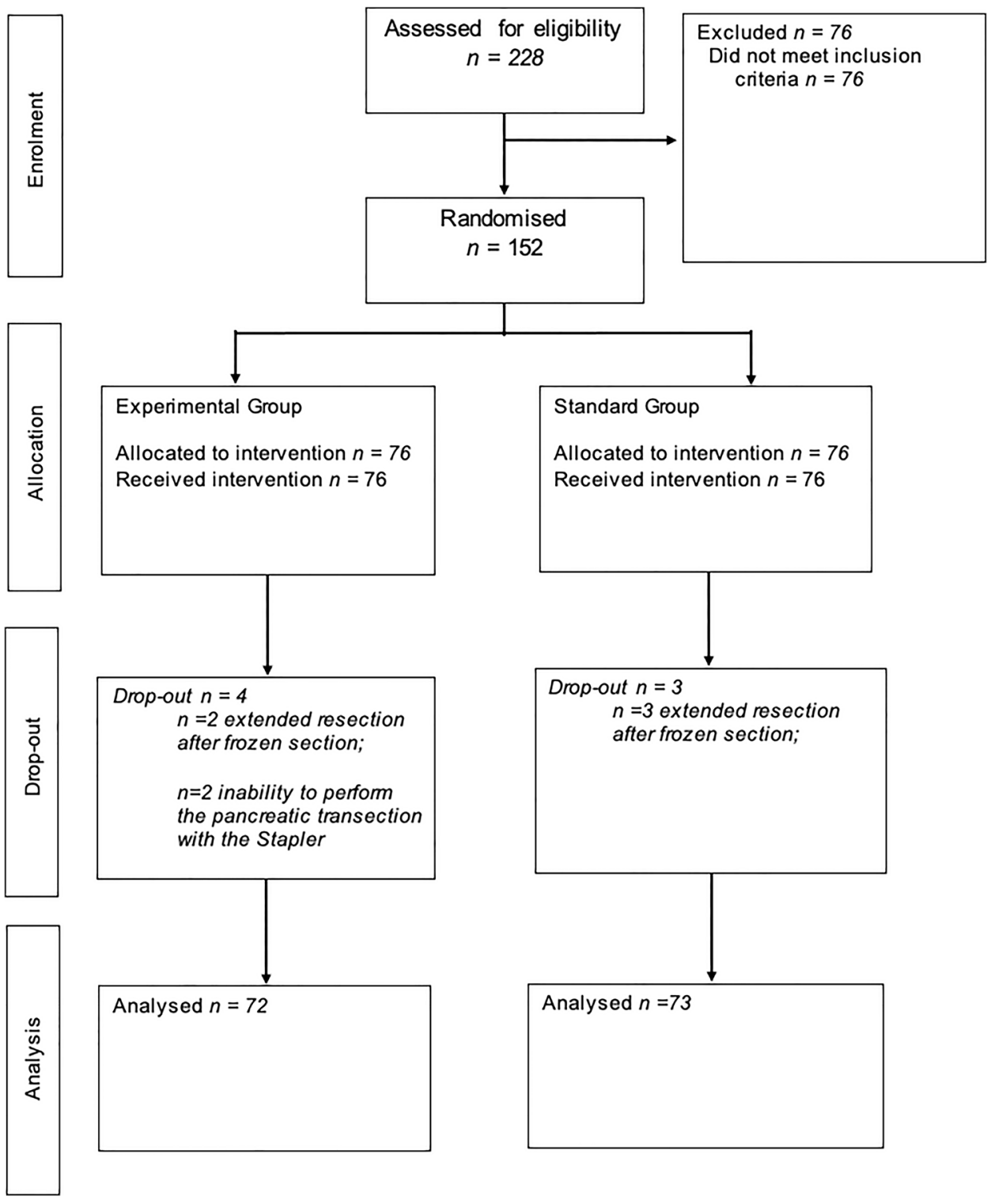

and was standardized across the participating institutions [22].

\section{Outcomes}

The primary endpoint was the incidence of POPF as defined by the International Study Group of Pancreatic Surgery [23]. Secondary endpoints were any complications, classified according to the Clavien-Dindo score [24], major complications, defined as Clavien-Dindo grade III or higher, abdominal collections, delayed gastric emptying (DGE) and post-pancreatectomy hemorrhage (PPH), classified according to the International Study Group on Pancreatic Surgery definitions $[25,26]$, postoperative hospital stay (including readmission), and 90-day mortality. Follow-up visits were carried out at 30 and 90 days from the index operation.

\section{Statistical analysis}

The study was designed hypothesizing that stapled transection was superior to ultrasonic transection. The sample size was calculated based on previously published institutional retrospective data reporting a $40 \%$ and $12 \%$ POPF rates following ultrasonic and stapled transection, respectively [15]. Assuming a $20 \%$ delta in the prospective trial, at a $5 \%$ alpha and $80 \%$ power (1-beta), the required sample size was 138 patients (69 per arm) according to the continuity corrected Z-Test with unpooled variance. Adjustment for post-randomization drop-out was made expecting a $10 \%$ rate of transection margin positivity on frozen section analysis, leading to a total sample size of 152 patients (76 per arm). Demographic and clinical characteristics were age, gender, American Society of Anesthesiologists (ASA) score, body 
mass index (BMI, $\mathrm{kg} / \mathrm{m} 2$ ) categorized based on WHO classification [27], diabetes mellitus, age-adjusted Charlson comorbidity index score [28], chronic steroid therapy, neoadjuvant chemotherapy. Surgical variables included operative approach, conversion from minimally invasive to open approach, splenectomy, pancreatic gland thickness measured by intraoperative ultrasound at the point of transection, transection level categorized into gastroduodenal artery level, pancreatic neck, and left border of the aorta or more distal, vascular venous resection, intraoperative blood loss $(\mathrm{mL})$, and operating time (minutes). In the stapled transection arm, the compression ratio (defined as the pancreas thickness divided by the closed length of the stapler), and the height difference (defined as the difference between the pancreatic thickness and the closed length of the stapler) were calculated $[12,29]$. The values of closed length were defined per the manufacturer specifications.

Continuous variables were expressed as means with standard deviation or medians with interquartile range (IQR) and compared using $t$-test or Mann-Whitney test, as appropriate. Categorical variables were expressed as absolute numbers and percentages and compared using chi-square test or Fisher's exact test. All tests were two-tailed. Binary logistic regression analysis was performed to investigate factors associated with POPF. Factors with a $p$-value $<0.1$ on univariable analysis were entered in the model. Data are presented with odds ratios and $95 \%$ confidence intervals. A $p$-value $<0.05$ was considered statistically significant. Data were analyzed using the Statistical Package for Social Sciences software, v25.0 for Windows (SPSS, Inc, Chicago, IL, USA).

\section{Results}

\section{General characteristics}

A total of 152 patients met the inclusion criteria and were randomized (Fig. 1). Due to a positive transection margin on frozen section analysis requiring further resection, seven patients were excluded post-randomization. Therefore, the final population comprised 72 patients in the stapled transection arm and 73 patients in the ultrasonic transection arm. The baseline characteristics by randomization arm are outlined in Table 1. The median pancreatic thickness measured intraoperatively at the transection level was $12 \mathrm{~mm}$ in both groups.

\section{Primary endpoint}

Overall, 23 patients (16\%) developed POPF (Table 2). There were 19 grade B (14\%) and 4 grade C fistulas (2\%). The incidence of POPF was similar between groups (12\% in stapled transection versus $19 \%$ in ultrasonic dissection, $p=0.191$ ). Biochemical leak (BL) occurred in 42 patients (29\%), 21 patients in each arm $(p=0.552)$.

\section{Secondary endpoints}

Table 2 shows the postoperative outcomes. In all, 57 patients (39\%) had any complication, without differences between groups (35\% in stapled transection versus $44 \%$ in ultrasonic transection, $p=0.170$ ). There was an increased incidence of abdominal collections in the ultrasonic dissection group ( $32 \%$ versus $14 \%, p=0.009$ ). In both groups, one-third of patients with POPF required a percutaneous drain $(p=0.169)$. Five patients (3\%) underwent reoperation, mostly for a hemorrhage (three of five patients), while the other two of five patients undergoing re-operation presented with sepsis due to infected POPF. There was one postoperative death in the ultrasonic dissection group. This patient died on postoperative day four of a sudden aortic arch dissection that was confirmed on autopsy. The median length of stay was similar between groups ( 8 days, $p=0.880$ ).

Univariable analysis of factors associated with POPF, shown in Table 3, revealed a significant association with BMI, pancreas transection level, and intraoperative blood transfusion. The mean intraoperative estimated blood loss of transfused patients was $650 \mathrm{cc}$. Only in two cases there was massive intraoperative bleeding $(>2000 \mathrm{cc})$. In the stapled transection group, the compression rate and the height difference were not correlated with POPF ( $p=0.362$ and $p=0.979$, respectively). Intraoperative blood transfusion was the only factor independently associated with POPF (OR 4.8, 95\% CI 1.2-20, $p=0.032$ ) on logistic regression analysis (Table 4).

\section{Discussion}

The present randomized clinical trial of stapled versus ultrasonic transection in DP demonstrated no significant difference in POPF rates. Analysis of secondary outcomes revealed a greater incidence of abdominal collections in the ultrasonic dissection arm, although the need for percutaneous drains was comparable between groups. POPF therefore remains a clinically relevant and unsolved issue for patients undergoing elective DP, with a formation process likely independent on the surgical technique adopted for resection and closure of the pancreatic remnant. Our findings indeed resonate with previously published randomized controlled trials that did not identify an optimal transection method able to decrease POPF [30].

To the best of our knowledge, this is the first randomized trial of a triple-row stapler reinforced with a preloaded PGA felt. Previous studies had already shown that wrapping the 
Table 1 Demographic, intraoperative, and pathological data

\begin{tabular}{|c|c|c|c|}
\hline \multicolumn{4}{|l|}{ Study population $n=145$} \\
\hline & Total $n^{\circ}(\%)$ & $\begin{array}{l}\text { Stapled transec- } \\
\text { tion } 72(50 \%)\end{array}$ & $\begin{array}{l}\text { Ultrasonic } \\
\text { transection } 73 \\
(50 \%)\end{array}$ \\
\hline Age (years, IQR) & $60[50-70]$ & $62[50-70]$ & $60[50-69]$ \\
\hline Gender (Female) & $87(60)$ & $48(67)$ & $39(53)$ \\
\hline BMI $\left(\mathrm{Kg} / \mathrm{m}^{2}, \mathrm{IQR}\right)$ & $25[22-27]$ & $24[21-27]$ & $25[22-28]$ \\
\hline Diabetes & $24(17)$ & $13(18)$ & $11(15)$ \\
\hline ASA score $\geq$ III & $18(12)$ & $8(11)$ & $10(14)$ \\
\hline Charlson Age $>4$ & $48(33)$ & $25(35)$ & $23(32)$ \\
\hline Neoadjuvant therapy & $31(21)$ & $15(21)$ & $16(22)$ \\
\hline Minimally invasive & $59(41)$ & $29(40)$ & $30(41)$ \\
\hline Conversion $^{\#}$ & $2(3)$ & $0(0)$ & $2(7)$ \\
\hline Spleen preservation & $24(17)$ & $10(14)$ & $14(19)$ \\
\hline Vascular resection & $4(3)$ & $0(0)$ & $4(6)$ \\
\hline \multicolumn{4}{|l|}{ Transection level } \\
\hline Pancreatic neck & $104(72)$ & $50(69)$ & $54(74)$ \\
\hline GDA level & $3(2)$ & $3(4)$ & $0(0)$ \\
\hline Left aortic border & $38(26)$ & $19(26)$ & $19(26)$ \\
\hline IOUS thickness (mm, IQR) & $12[10-14]$ & 12 [10-14] & $12[10-15]$ \\
\hline Duration of Surgery (minutes, IQR) & $251[201-334]$ & $246[201-321]$ & 257 [202-335] \\
\hline EBL (cc, IQR) & $100[50-300]$ & $100[100-300]$ & $150[50-300]$ \\
\hline Blood transfusion & $11(8)$ & $4(6)$ & $7(10)$ \\
\hline \multicolumn{4}{|l|}{ Pathology, No. (\%) } \\
\hline PDAC & $54(37)$ & $32(44)$ & $22(30)$ \\
\hline pNET & $39(27)$ & $17(24)$ & $22(30)$ \\
\hline IPMN & $8(6)$ & $4(6)$ & $4(6)$ \\
\hline $\mathrm{MCN} / \mathrm{SCN}$ & $30(20)$ & $16(22)$ & $14(19)$ \\
\hline SPN & $6(4)$ & $2(3)$ & $4(6)$ \\
\hline Other & $8(6)$ & $1(1)$ & $7(9)$ \\
\hline
\end{tabular}

\# Referred to minimally invasive procedures

$B M I$ body mass index, ASA American society of Anesthesiology, GDA gastroduodenal artery, IOUS intraoperative ultrasound, $E B L$ estimated blood loss, $P D A C$ pancreatic ductal adenocarcinoma, $p N E T$ pancreatic neuroendocrine tumor, $I P M N$ intraductal papillary mucinous neoplasm, $M C N$ mucinous cystic neoplasm, $S C N$ serous cystic neoplasm, $S P N$ solid pseudopapillary neoplasm pancreatic stump with a PGA mesh decreased the rate of POPF [31, 32], and triple-row stapler had been associated with less POPF compared with the double-row staplers [33]. The Endo GIA Reinforced Reload with Tri-Staple Technology® has been available at the authors' institution since its introduction into the market and has been employed at the surgeon's discretion for parenchymal transection in DP. A retrospective propensity-matched analysis comparing surgical outcomes with ultrasonic dissection (HARMONIC ${ }^{\circledR}$ Focus + or Ace + ) showed a significantly decreased rate of POPF in the reinforced Tri-Staple group (12\% versus $40 \%$ ), constituting the backbone for the present trial [15]. As suggested by earlier studies, patients with a parenchymal thickness $>17 \mathrm{~mm}$ were excluded because of a very high incidence of POPF that was independent on the type of cartridge, because of stapler closure failure of parenchymal crushing [12]. In patients who were randomized to stapled transection we gradually compressed the pancreas with the stapler for about 2-3 min, then divided the parenchyma and released the device slowly. This has been shown to help avoiding the development of POPF [34]. Nonetheless, the choice of the stapler cartridge was left at the single surgeon's discretion. While cartridges with closed length $<15 \mathrm{~mm}$ (i.e., purple) have been shown to be particularly suitable for thin pancreata $(<12 \mathrm{~mm})$, in thicker glands a longer staple height has been recommended (i.e., black) although no particular cartridge has proven to outperform the others.

In the ultrasonic dissection arm, the pancreas was transected and simultaneously sealed by coaptive coagulation at the lowest vibration level. Experimental studies proved that the lateral thermal spread is limited to $0-2 \mathrm{~mm}$ beyond the tissue grasped within the forceps of the device [35]. 
Table 2 Postoperative data

\begin{tabular}{lllll}
\hline Study population $n=145$ & & & & \\
\hline & Total N (\%) & $\begin{array}{l}\text { Stapled transec- } \\
\text { tion } 72(50 \%)\end{array}$ & $\begin{array}{l}\text { Ultrasonic transec- } \\
\text { tion 73 (50\%) }\end{array}$ & $p$-value \\
\hline Any complication & $57(39)$ & $25(35)$ & $32(44)$ & 0.170 \\
POPF & $23(16)$ & $9(12)$ & $14(19)$ & 0.191 \\
Grade B & $19(14)$ & $8(12)$ & $11(16)$ & \\
Grade C & $4(2)$ & $1(1)$ & $3(4)$ & 0.552 \\
Biochemical leak & $42(29)$ & $21(29)$ & $21(29)$ & $\mathbf{0 . 0 0 9}$ \\
Abdominal collection & $33(23)$ & $10(14)$ & $23(32)$ & 0.169 \\
Percutaneous drain & $10(7)$ & $3(4)$ & $7(10)$ & 0.305 \\
DGE & $4(3)$ & $3(4)$ & $8(1)$ & 0.109 \\
PPH & $11(8)$ & $3(4)$ & $10(13)$ & 0.314 \\
ICU Admission & $17(12)$ & $7(9)$ & $13(18)$ & 0.074 \\
Clavien-Dindo $\geq 3$ & $19(13)$ & $6(8)$ & $8[6-12]$ & 0.880 \\
Length of stay (days, IQR) & $8[6-13]$ & $8[6-13]$ & $3(4)$ & 0.507 \\
Reoperation & $5(3)$ & $2(3)$ & $10(14)$ & 0.083 \\
Readmission & $14(10)$ & $4(6)$ & $1(1)$ & 0.500 \\
Mortality & $1(1)$ & $0(0)$ & & \\
\hline
\end{tabular}

Bold value indicates statistical difference $(p$-value $<0.05)$

$P O P F$ postoperative pancreatic fistula, $D G E$ delayed gastric empty, $P P H$ Post pancreatectomy hemorrhage, $I C U$ intensive care unit

The decreased propensity for collateral thermal damage is an important putative advantage of the Harmonic scalpel, particularly when compared with other energy devices such as monopolar and bipolar diathermy, which are commonly used for pancreatic transection in DP [30]. However, an independent association between ultrasonic transection and a slower POPF healing has been suggested by our group [36]. Whether this depends on thermal effects has to be fully elucidated.

Analysis of factors associated with POPF suggested that BMI and the anatomic transection level play an integral role to the process. BMI is indeed a surrogate of fatty infiltration that has been shown to correlate with a complicated clinical course [37]. Even the transection level has been widely linked to POPF, because the pancreas shape and thickness are different at the gastroduodenal artery level, at the neck, or in the body and tail $[8,11]$. Nonetheless, only intraoperative blood transfusion was independently associated with POPF on multivariable analysis. This is in accordance with a recent systematic review and meta-analysis, and might serve as a surrogate parameter for pancreatic stump ischemia [38]. Taken together, these results emphasize the need for perioperative composite scores to predict high-risk scenarios and help establishing individualized prevention and mitigation strategies. While these tools have been derived and successfully validated in pancreatoduodenectomy [39], previous efforts in large, multi-institutional DP series have proven elusive [40].

The study has some limitations. First, sub-analysis of stapler cartridges was not done. The liberal use of purple or black cartridges with PGA reinforcement possibly introduced a bias, despite the compression rate and the height difference were not associated with POPF. Another limitation could be the difference in the anatomic point of parenchymal transection. Nonetheless, the point of transection was dictated by the underlying pathology, with parenchyma-sparing procedures being favored in the context of benign to low-grade neoplasms, and this parameter did not result to be a risk factor at the adjusted analysis.

In conclusion, the present randomized controlled trial of stapled transection using a PGA-reinforced triple-row stapler versus ultrasonic transection with HARMONIC® energy devices in elective DP demonstrated no significant difference in POPF rates and no substantial clinical impact 
Table 3 Univariable analysis of factors associated with POPF

\begin{tabular}{|c|c|c|c|}
\hline \multicolumn{4}{|l|}{ Study population $n=145$} \\
\hline & POPF $23(16 \%)$ & No POPF $122(84 \%)$ & $p$-value \\
\hline Age (years, IQR) & $62[55-71]$ & $60[50-69]$ & 0.564 \\
\hline Sex (Female) & $11(48 \%)$ & $76(62 \%)$ & 0.143 \\
\hline $\mathrm{BMI}\left(\mathrm{Kg} / \mathrm{m}^{2}, \mathrm{IQR}\right)$ & $26[25-29]$ & $24[21-27]$ & 0.013 \\
\hline Diabetes & $2(9 \%)$ & $22(18 \%)$ & 0.218 \\
\hline ASA score $\geq$ III & $3(13 \%)$ & $15(12 \%)$ & 0.573 \\
\hline Charlson age $>4$ & $8(35 \%)$ & $40(33 \%)$ & 0.514 \\
\hline Neoadjuvant therapy & $5(22 \%)$ & $26(21 \%)$ & 0.577 \\
\hline Thickness neck (mm, IQR) & $14[12-15]$ & $11[9-13]$ & $<0.001$ \\
\hline Duct size (mm, IQR) & $2[1-3]$ & $1[1,2]$ & 0.482 \\
\hline Minimally invasive DP & $12(52 \%)$ & $47(39 \%)$ & 0.161 \\
\hline Spleen preservation & $4(17 \%)$ & $20(16 \%)$ & 0.555 \\
\hline Vascular resection & $1(4 \%)$ & $3(3 \%)$ & 0.503 \\
\hline Transection level & & & 0.040 \\
\hline Pancreatic neck & $14(13 \%)$ & $90(87 \%)$ & \\
\hline GDA level & $2(67 \%)$ & $1(33 \%)$ & \\
\hline Left aortic border & $7(18 \%)$ & $31(82 \%)$ & \\
\hline IOUS thickness (mm, IQR) & 13 [11-15] & $12[10-14]$ & 0.307 \\
\hline Compression rate $^{\#}(\mathrm{~mm}, \mathrm{SD})$ & $3,5 \pm 0,5$ & $3,4 \pm 0,6$ & 0.362 \\
\hline Height difference ${ }^{\#}(\mathrm{~mm}, \mathrm{SD})$ & $8,3 \pm 1,8$ & $8,3 \pm 2,2$ & 0.979 \\
\hline Duration of Surgery (minutes, IQR) & $293[216-378]$ & $246[201-321]$ & 0.126 \\
\hline $\mathrm{EBL}(\mathrm{cc}, \mathrm{IQR})$ & $200[75-300]$ & $100[50-300]$ & 0.399 \\
\hline Blood transfusion & $5(22 \%)$ & $6(5 \%)$ & 0.016 \\
\hline Pathology PDAC & $10(19 \%)$ & $13(14 \%)$ & 0.326 \\
\hline
\end{tabular}

Bold values indicate statistical difference ( $p$-value $<0.05$ )

$B M I$ body mass index, ASA American society of Anesthesiology, GDA gastroduodenal artery, IOUS intraoperative ultrasound, $E B L$ estimated blood loss, $P D A C$ pancreatic ductal adenocarcinoma

\#Related only to the reinforced stapler group
Table 4 Logistic regression of factors associated with POPF

\begin{tabular}{llll}
\hline \multicolumn{1}{l}{ Study population $n=145$} & & \\
\hline & POPF & $p$-value & OR (CI 95\%) \\
\hline BMI $\left(\mathrm{Kg} / \mathrm{m}^{2}\right)$ & & & \\
$\quad<24,9 \mathrm{~kg} / \mathrm{m}^{2}$ & $7(10 \%)$ & 1 & $\backslash$ \\
$25-29,9 \mathrm{~kg} / \mathrm{m}^{2}$ & $11(20 \%)$ & 0.209 & $1.9(0.6-5.8)$ \\
$>30 \mathrm{~kg} / \mathrm{m}^{2}$ & $5(29 \%)$ & 0.924 & $1(0.4-2.3)$ \\
Transection level & & & \\
Pancreatic neck & $14(13 \%)$ & 1 & $\backslash$ \\
GDA level & $2(67 \%)$ & 0.357 & $1.4(0.6-3.4)$ \\
Left aortic border & $7(18 \%)$ & 0.114 & $0.2(0.3-1.5)$ \\
Blood transfusion & & & \\
No & & 1 & $\backslash$ \\
Yes & $5(46 \%)$ & $\mathbf{0 . 0 3 2}$ & $4.8(1.2-20)$ \\
\hline
\end{tabular}

Bold value indicates statistical difference $(p$-value $<0.05$ )

$B M I$ body mass index, GDA gastroduodenal artery, $P O P F$ postoperative pancreatic fistula on other secondary endpoints. Therefore, the optimal technique for the management of pancreatic stump in resection of the left pancreas remains unclear and warrants further investigation.

Acknowledgements The present study was performed on the behalf of the EAES in the EAES Research grant program 2018.

Funding Open access funding provided by Università degli Studi di Verona within the CRUI-CARE Agreement.

\section{Declarations}

Disclosures Luca Landoni MD, Matteo De Pastena, Martina Fontana, Giuseppe Malleo, Alessandro Esposito, Luca Casetti, Giovanni Marchegiani, Massimiliano Tuveri, Antonio Pea, Marco Ramera, Alex Borin, Alessandro Giardino, Isabella Frigerio, Roberto Girelli, Claudio Bassi, Giovanni Butturini Roberto Salvia have no conflicts of interest or financial ties to disclose. 
Open Access This article is licensed under a Creative Commons Attribution 4.0 International License, which permits use, sharing, adaptation, distribution and reproduction in any medium or format, as long as you give appropriate credit to the original author(s) and the source, provide a link to the Creative Commons licence, and indicate if changes were made. The images or other third party material in this article are included in the article's Creative Commons licence, unless indicated otherwise in a credit line to the material. If material is not included in the article's Creative Commons licence and your intended use is not permitted by statutory regulation or exceeds the permitted use, you will need to obtain permission directly from the copyright holder. To view a copy of this licence, visit http://creativecommons.org/licenses/by/4.0/.

\section{References}

1. Kleeff J, Diener MK, Z'graggen K, Hinz U, Wagner M, Bachmann J, Zehetner J, Müller MW, Friess H, Büchler MW (2007) Distal pancreatectomy: risk factors for surgical failure in 302 consecutive cases. Ann Surg 245:573-582. https://doi.org/10.1097/01.sla. 0000251438.43135.fb

2. Knaebel HP, Diener MK, Wente MN, Büchler MW, Seiler CM (2005) Systematic review and meta-analysis of technique for closure of the pancreatic remnant after distal pancreatectomy. Br J Surg 92:539-546. https://doi.org/10.1002/bjs.5000

3. Diener MK, Seiler CM, Rossion I, Kleeff J, Glanemann M, Butturini G, Tomazic A, Bruns CJ, Busch ORC, Farkas S, Belyaev O, Neoptolemos JP, Halloran C, Keck T, Niedergethmann M, Gellert K, Witzigmann H, Kollmar O, Langer P, Steger U, Neudecker J, Berrevoet F, Ganzera S, Heiss MM, Luntz SP, Bruckner T, Kieser M, Büchler MW (2011) Efficacy of stapler versus hand-sewn closure after distal pancreatectomy (DISPACT): a randomised, controlled multicentre trial. Lancet Lond Engl 377:1514-1522. https://doi.org/10.1016/S0140-6736(11)60237-7

4. Bilimoria MM, Cormier JN, Mun Y, Lee JE, Evans DB, Pisters PWT (2003) Pancreatic leak after left pancreatectomy is reduced following main pancreatic duct ligation. Br J Surg 90:190-196. https://doi.org/10.1002/bjs.4032

5. Sheehan MK, Beck K, Creech S, Pickleman J, Aranha GV (2002) Distal pancreatectomy: does the method of closure influence fistula formation? Am Surg 68:264-267

6. Suzuki Y, Fujino Y, Tanioka Y, Hori Y, Ueda T, Takeyama Y, Tominaga M, Ku Y, Yamamoto YM, Kuroda Y (1999) Randomized clinical trial of ultrasonic dissector or conventional division in distal pancreatectomy for non-fibrotic pancreas. Br J Surg 86:608-611. https://doi.org/10.1046/j.1365-2168.1999.01120.x

7. Kawai M, Hirono S, Okada K-I, Sho M, Nakajima Y, Eguchi H, Nagano H, Ikoma H, Morimura R, Takeda Y, Nakahira S, Suzumura K, Fujimoto J, Yamaue H (2016) Randomized controlled trial of pancreaticojejunostomy versus stapler closure of the pancreatic stump during distal pancreatectomy to reduce pancreatic fistula. Ann Surg 264:180-187. https://doi.org/10.1097/SLA. 0000000000001395

8. Hassenpflug M, Hinz U, Strobel O, Volpert J, Knebel P, Diener MK, Doerr-Harim C, Werner J, Hackert T, Büchler MW (2016) Teres ligament patch reduces relevant morbidity after distal pancreatectomy (the DISCOVER randomized controlled trial). Ann Surg 264:723-730. https://doi.org/10.1097/SLA.0000000000 001913

9. Hüttner FJ, Mihaljevic AL, Hackert T, Ulrich A, Büchler MW, Diener MK (2016) Effectiveness of Tachosil(®) in the prevention of postoperative pancreatic fistula after distal pancreatectomy: a systematic review and meta-analysis. Langenbecks Arch Surg 401:151-159. https://doi.org/10.1007/s00423-016-1382-7
10. Zhang H, Zhu F, Shen M, Tian R, Shi CJ, Wang X, Jiang JX, Hu J, Wang M, Qin RY (2015) Systematic review and meta-analysis comparing three techniques for pancreatic remnant closure following distal pancreatectomy. Br J Surg 102:4-15. https://doi.org/10. 1002/bjs. 9653

11. Ban D, Shimada K, Konishi M, Saiura A, Hashimoto M, Uesaka K (2012) Stapler and nonstapler closure of the pancreatic remnant after distal pancreatectomy: multicenter retrospective analysis of 388 patients. World J Surg 36:1866-1873. https://doi.org/10.1007/ s00268-012-1595-Z

12. Kim H, Jang J-Y, Son D, Lee S, Han Y, Shin YC, Kim JR, Kwon W, Kim S-W (2016) Optimal stapler cartridge selection according to the thickness of the pancreas in distal pancreatectomy. Medicine (Baltimore) 95:e4441. https://doi.org/10.1097/MD.00000 00000004441

13. Karabicak I, Satoi S, Yanagimoto H, Yamamoto T, Yamaki S, Kosaka H, Hirooka S, Kotsuka M, Michiura T, Inoue K, Matsui Y, Kon M (2017) Comparison of surgical outcomes of three different stump closure techniques during distal pancreatectomy. Pancreatol Off J Int Assoc Pancreatol IAP Al 17:497-503. https://doi.org/10.1016/j.pan.2017.04.005

14. Yamashita Y-I, Tsujita E, Chikamoto A, Imai K, Kaida T, Yamao T, Umezaki N, Nakagawa S, Hashimoto D, Baba H (2017) Linear stapling device with pre-attached bioabsorbable polyglycolic acid felt reduces postoperative pancreatic fistula after distal pancreatectomy. Anticancer Res 37:1865-1868.

15. Pulvirenti A, Landoni L, Borin A, De Pastena M, Fontana M, Pea A, Esposito A, Casetti L, Tuveri M, Paiella S, Marchegiani G, Malleo G, Salvia R, Bassi C (2019) Reinforced stapler versus ultrasonic dissector for pancreatic transection and stump closure for distal pancreatectomy: A propensity matched analysis. Surgery. https://doi.org/10.1016/j.surg.2019.02.016

16. Schulz KF, Altman DG, Moher D, CONSORT Group (2010) CONSORT 2010 statement: updated guidelines for reporting parallel group randomised trials. BMJ 340:c332. https://doi.org/ 10.1136/bmj.c332

17. Kang MK, Kim H, Byun Y, Han Y, Choi YJ, Kang JS, Kwon W, Han IW, Shin SH, Choi DW, You Y, Heo JS, Jang J-Y (2020) Optimal stapler cartridge selection to reduce post-operative pancreatic fistula according to the pancreatic characteristics in stapler closure distal pancreatectomy. HPB. https://doi.org/10. 1016/j.hpb.2020.09.004

18. Melotti G, Butturini G, Piccoli M, Casetti L, Bassi C, Mullineris B, Lazzaretti MG, Pederzoli P (2007) Laparoscopic distal pancreatectomy: results on a consecutive series of 58 patients. Ann Surg 246:77-82. https://doi.org/10.1097/01.sla.0000258607. 17194.2b

19. Esposito A, Casetti L, De Pastena M, Ramera M, Montagnini G, Landoni L, Bassi C, Salvia R (2020) Robotic spleen-preserving distal pancreatectomy: the Verona experience. Updat Surg. https://doi.org/10.1007/s13304-020-00731-8

20. De Pastena M, Esposito A, Paiella S, Surci N, Montagnini G, Marchegiani G, Malleo G, Secchettin E, Casetti L, Ricci C, Landoni L, Bovo C, Bassi C, Salvia R (2020) Cost-effectiveness and quality of life analysis of laparoscopic and robotic distal pancreatectomy: a propensity score-matched study. Surg Endosc. https://doi.org/10.1007/s00464-020-07528-1

21. Salvia R, Malleo G, Marchegiani G, Butturini G, Esposito A, Bassi C (2014) Pancreaticoduodenectomy with harmonic focust curved shears for cancer. Dig Surg 31:249-254. https://doi.org/ 10.1159/000363071

22. Bassi C, Molinari E, Malleo G, Crippa S, Butturini G, Salvia R, Talamini G, Pederzoli P (2010) Early versus late drain removal after standard pancreatic resections: results of a prospective randomized trial. Ann Surg 252:207. https://doi.org/10.1097/ SLA.0b013e3181e61e 88 
23. Bassi C, Marchegiani G, Dervenis C, Sarr M, Abu Hilal M, Adham M, Allen P, Andersson R, Asbun HJ, Besselink MG, Conlon K, Del Chiaro M, Falconi M, Fernandez-Cruz L, Fernandez-Del Castillo C, Fingerhut A, Friess H, Gouma DJ, Hackert T, Izbicki J, Lillemoe KD, Neoptolemos JP, Olah A, Schulick R, Shrikhande SV, Takada T, Takaori K, Traverso W, Vollmer CR, Wolfgang CL, Yeo CJ, Salvia R, Buchler M, International Study Group on Pancreatic Surgery (ISGPS) (2017) The 2016 update of the International Study Group (ISGPS) definition and grading of postoperative pancreatic fistula: 11 Years After. Surgery 161:584-591. https://doi.org/10.1016/j. surg.2016.11.014

24. Dindo D, Demartines N, Clavien P-A (2004) Classification of Surgical Complications. Ann Surg 240:205-213. https://doi.org/ 10.1097/01.sla.0000133083.54934.ae

25. Wente MN, Bassi C, Dervenis C, Fingerhut A, Gouma DJ, Izbicki JR, Neoptolemos JP, Padbury RT, Sarr MG, Traverso LW, Yeo CJ, Büchler MW (2007) Delayed gastric emptying (DGE) after pancreatic surgery: a suggested definition by the International Study Group of Pancreatic Surgery (ISGPS). Surgery 142:761-768. https://doi.org/10.1016/j.surg.2007.05.005

26. Wente MN, Veit JA, Bassi C, Dervenis C, Fingerhut A, Gouma DJ, Izbicki JR, Neoptolemos JP, Padbury RT, Sarr MG, Yeo CJ, Büchler MW (2007) Postpancreatectomy hemorrhage (PPH): an International Study Group of Pancreatic Surgery (ISGPS) definition. Surgery 142:20-25. https://doi.org/10.1016/j.surg.2007.02. 001

27. Weir CB, Jan A (2020) BMI Classification Percentile And Cut Off Points. In: StatPearls. StatPearls Publishing, Treasure Island (FL)

28. Chang C-M, Yin W-Y, Wei C-K, Wu C-C, Su Y-C, Yu C-H, Lee C-C (2016) Adjusted Age-Adjusted Charlson Comorbidity Index Score as a Risk Measure of Perioperative Mortality before Cancer Surgery. PLoS ONE 11:e0148076. https://doi.org/10.1371/journ al.pone. 0148076

29. Nishikawa M, Yamamoto J, Hoshikawa M, Einama T, Noro T, Aosasa S, Tsujimoto H, Ueno H, Kishi Y (2020) Stapler sizes optimized for pancreatic thickness can reduce pancreatic fistula incidence after distal pancreatectomy. Surg Today 50:623-631. https://doi.org/10.1007/s00595-019-01929-Z

30. Miao Y, Lu Z, Yeo CJ, Vollmer CM, Fernandez-Del Castillo C, Ghaneh P, Halloran CM, Kleeff J, de Rooij T, Werner J, Falconi M, Friess H, Zeh HJ, Izbicki JR, He J, Laukkarinen J, Dejong CH, Lillemoe KD, Conlon K, Takaori K, Gianotti L, Besselink MG, Del Chiaro M, Montorsi M, Tanaka M, Bockhorn M, Adham M, Oláh A, Salvia R, Shrikhande SV, Hackert T, Shimosegawa T, Zureikat AH, Ceyhan GO, Peng Y, Wang G, Huang X, Dervenis C, Bassi C, Neoptolemos JP, Büchler MW, International Study Group of Pancreatic Surgery (ISGPS) (2020) Management of the pancreatic transection plane after left (distal) pancreatectomy: Expert consensus guidelines by the International Study Group of Pancreatic Surgery (ISGPS). Surgery 168:72-84. https://doi.org/ 10.1016/j.surg.2020.02.018

31. Park JS, Lee D-H, Jang J-Y, Han Y, Yoon DS, Kim JK, Han H-S, Yoon Y, Hwang D, Kang CM, Hwang HK, Lee WJ, Heo J, Chang YR, Kang MJ, Shin YC, Chang J, Kim H, Jung W, Kim S-W (2016) Use of TachoSil(®) patches to prevent pancreatic leaks after distal pancreatectomy: a prospective, multicenter, randomized controlled study. J Hepato-Biliary-Pancreat Sci 23:110117. https://doi.org/10.1002/jhbp.310
32. Malleo G, Marchegiani G, Borin A, Capelli P, Accordini F, Butturini G, Pederzoli P, Bassi C, Salvia R (2015) Observational study of the incidence of pancreatic and extrapancreatic malignancies during surveillance of patients with branch-duct intraductal papillary mucinous neoplasm. Ann Surg 261:984-990. https://doi. org/10.1097/SLA.0000000000000884

33. Jang J-Y, Shin YC, Han Y, Park JS, Han H-S, Hwang HK, Yoon DS, Kim JK, Yoon YS, Hwang DW, Kang CM, Lee WJ, Heo JS, Kang MJ, Chang YR, Chang J, Jung W, Kim S-W (2017) Effect of polyglycolic acid mesh for prevention of pancreatic fistula following distal pancreatectomy: a randomized clinical trial. JAMA Surg 152:150-155. https://doi.org/10.1001/jamasurg.2016.3644

34. Asbun HJ, Van Hilst J, Tsamalaidze L, Kawaguchi Y, Sanford D, Pereira L, Besselink MG, Stauffer JA (2020) Technique and audited outcomes of laparoscopic distal pancreatectomy combining the clockwise approach, progressive stepwise compression technique, and staple line reinforcement. Surg Endosc 34:231239. https://doi.org/10.1007/s00464-019-06757-3

35. Sutton PA, Awad S, Perkins AC, Lobo DN (2010) Comparison of lateral thermal spread using monopolar and bipolar diathermy, the Harmonic Scalpel and the Ligasure. Br J Surg 97:428-433. https://doi.org/10.1002/bjs.6901

36. Andrianello S, Marchegiani G, Bannone E, Vacca P, Esposito A, Casetti L, Salvia R, Bassi C (2020) Predictors of pancreatic fistula healing time after distal pancreatectomy. J Hepato-BiliaryPancreat Sci. https://doi.org/10.1002/jhbp.843

37. Mathur A, Pitt HA, Marine M, Saxena R, Schmidt CM, Howard TJ, Nakeeb A, Zyromski NJ, Lillemoe KD (2007) Fatty pancreas: a factor in postoperative pancreatic fistula. Ann Surg 246:10581064. https://doi.org/10.1097/SLA.0b013e31814a6906

38. Peng Y-P, Zhu X-L, Yin L-D, Zhu Y, Wei J-S, Wu J-L, Miao Y (2017) Risk factors of postoperative pancreatic fistula in patients after distal pancreatectomy: a systematic review and meta-analysis. Sci Rep. https://doi.org/10.1038/s41598-017-00311-8

39. Trudeau MT, Casciani F, Ecker BL, Maggino L, Seykora TF, Puri P, McMillan MT, Miller B, Pratt WB, Asbun HJ, Ball CG, Bassi C, Behrman SW, Berger AC, Bloomston MP, Callery MP, Castillo CF-D, Christein JD, Dillhoff ME, Dickson EJ, Dixon E, Fisher WE, House MG, Hughes SJ, Kent TS, Malleo G, Salem RR, Wolfgang CL, Zureikat AH, Vollmer CM, on the behalf of the Pancreas Fistula Study Group (2020) The fistula risk score catalog: toward precision medicine for pancreatic fistula after pancreatoduodenectomy. Ann Surg. https://doi.org/10.1097/SLA.0000000000004068

40. Ecker BL, McMillan MT, Allegrini V, Bassi C, Beane JD, Beckman RM, Behrman SW, Dickson EJ, Callery MP, Christein JD, Drebin JA, Hollis RH, House MG, Jamieson NB, Javed AA, Kent TS, Kluger MD, Kowalsky SJ, Maggino L, Malleo G, Valero V, Velu LKP, Watkins AA, Wolfgang CL, Zureikat AH, Vollmer CM (2019) Risk factors and mitigation strategies for pancreatic fistula after distal pancreatectomy: analysis of 2026 resections from the international, multi-institutional distal pancreatectomy study group. Ann Surg 269:143-149. https://doi.org/10.1097/ SLA.0000000000002491

Publisher's Note Springer Nature remains neutral with regard to jurisdictional claims in published maps and institutional affiliations. 